\title{
ANNÍBAL MARQUES DA COSTA E A "MATEMÁTICA EM VERSOS E PROSAS" - HISTÓRIAS DA MATEMÁTICA NA SÃO JOÃO DEL-REI DO INÍCIO DO SÉCULO XX *
}

\section{Anníbal Marques da Costa and the "Matemática em versos e prosas" - histories of mathematics in Sao João del-Rei in the early twentieth century}

Romélia Mara Alves Souto ${ }^{1}$

Sandra Freire da Silva ${ }^{2}$

\begin{abstract}
Resumo: Neste artigo, apresentamos os resultados de um estudo analítico-descritivo que realizamos da obra "Matemática em versos e prosas", de Anníbal Marques da Costa, encontrada no acervo do Clube Teatral Artur Azevedo, na Universidade Federal de São João del-Rei (UFSJ), em Minas Gerais. A obra é um manuscrito, em dois volumes, produzida entre 1942 e 1954, que, com explícita intenção de divulgação da matemática, embora nunca tenha sido impressa, trata de conceitos e propriedades da matemática elementar. A investigação possibilitou-nos elaborar uma descrição seguida de uma análise histórica e crítica do texto, que foi enriquecida pelo acréscimo de algumas informações sobre o autor e a época em que ele viveu.
\end{abstract}

Palavras-chave: História da Matemática. Educação matemática. Anníbal Marques da Costa. Matemática.

\begin{abstract}
This paper presents the results of an analytical-descriptive study of the book "Matemática em versos e prosas" by Anníbal Marques da Costa, found in Clube Teatral Artur Azevedo, archives from the Universidade Federal de São João del-Rei (UFSJ), in Minas Gerais. The book has never been published and is a manuscript in two volumes produced between 1942 and 1954 aiming to promote Mathematics. It deals with the concepts and properties of elementary mathematics. The research enabled the development of a description and a historical and critical analysis of the text, enriched by some information about the author and the time he lived.
\end{abstract}

Keywords: History of Mathematics. Mathematics education. Anníbal Marques da Costa. Mathematics.

\footnotetext{
* Esse trabalho contou com apoio do CNPq.

${ }^{1}$ Licenciada em Matemática, doutora em Educação Matemática. Docente, Departamento de Matemática e Estatística, Universidade Federal de São João del-Rei (UFSJ). São João del-Rei, MG, Brasil. <romelia@ufsj.edu.br>

${ }^{2}$ Graduanda do curso de Licenciatura em Matemática, UFSJ. São João del-Rei, MG, Brasil.

<sandrynhafs@yahoo.com.br>

${ }^{1}$ UFSJ/DEMAT. Praça Frei Orlando, 170

São João del-Rei, MG.

$36.300-000$ 


\section{Introdução}

Apresentamos, aqui, o resultado de um estudo analítico-descritivo da obra "Matemática em versos e prosas", de Anníbal Marques da Costa, encontrada no acervo do Clube Teatral Artur Azevedo, sob a guarda da Universidade Federal de São João del-Rei (UFSJ), em Minas Gerais.

O interesse pelo trabalho de Anníbal Marques da Costa surgiu a partir dos resultados obtidos em outra investigação que empreendemos, dessa vez sobre as obras raras e antigas relacionadas à matemática e ao seu ensino, existentes em dois importantes acervos de São João del-Rei: o da Biblioteca Municipal Batista Caetano D’Almeida e o do Grupo Teatral Artur Azevedo. Naquela oportunidade, realizamos um levantamento e catalogamos as obras encontradas que tratam de matemática e áreas afins ${ }^{3}$, entre as quais estava o texto escrito por Anníbal. A "Matemática em versos e prosas" é um manuscrito, em dois volumes, produzido no período compreendido entre 1942 e 1954. Com explícita intenção de divulgação da matemática, o texto trata de conceitos e propriedades da matemática elementar - "só alguns simples conhecimentos de Arithimética e Álgebra” - nas palavras do autor. O que relatamos aqui é o resultado de um estudo documental, no sentido atribuído por Fiorentini e Lorenzato (2007), cujo objeto foi esse manuscrito. Além de descrever e analisar os documentos, procuramos obter, também, informações sobre o autor. Para isso, consultamos jornais da época, livros de história e realizamos entrevistas com personalidades sanjoanenses que viveram na época em que os manuscritos foram produzidos. A todas as nossas fontes foram colocadas questões referentes: aos conteúdos de matemática tratados no documento investigado, à formação e atuação profissional do seu autor, à relação desse documento com o ensino da matemática, ao público ao qual se destinava o texto, ao alcance e influência do texto e de seu autor para a educação matemática da época, dentre outras questões que foram surgindo no desenvolvimento da pesquisa. A análise dos documentos permitiu ampliar nossa compreensão de alguns aspectos importantes relativos à história da cidade e da educação matemática em nossa região. As informações obtidas e as conclusões a que chegamos permitiram-nos construir uma "representação historiadora" - no dizer de Paul Ricoeur (2004) - de uma pequena fração do passado de São João del-Rei, expressa no relato que apresentamos neste artigo.

\section{São João del-Rei no contexto da pesquisa em História da Matemática no Brasil}

No Brasil, a História da Matemática começa a se delinear como área de pesquisa no final da década de setenta do século passado, com a realização, por brasileiros, dos primeiros doutoramentos na área. No entanto, é somente a partir dos últimos quinze anos que podemos

\footnotetext{
${ }^{3} \mathrm{O}$ catálogo com as obras relacionadas à Matemática e à Educação Matemática foi colocado à disposição da comunidade científica, e os resultados do levantamento a que nos referimos foram divulgados em Souto (2008). 
Annibal Marques da Costa e a "Matemática em versos e prosas"...

acusar a constituição e a institucionalização da História da Matemática como área de investigação acadêmico-científica em nosso país. Nesse período foram realizadas oito edições do Seminário Nacional de História da Matemática e cinco do Encontro Luso-Brasileiro de História da Matemática. Em 1999, foi fundada a Sociedade Brasileira de História da Matemática SBHMat. "As atas desses eventos e os mini-cursos publicados, juntamente com a criação de duas novas revistas, a Revista Brasileira de História da Matemática: an International Journal on the History of Mathematics e História e Educação Matemática, ambas sob o patrocínio da SBHMat, são evidências do crescente interesse na área" (D’AMBROSIO, 2005, p. 14).

Desde o início, o avanço da pesquisa na área, em nosso país, tem apresentado inúmeros reflexos na Educação Matemática. Segundo Baroni; Teixeira; Nobre (2005), no cenário nacional, tanto indivíduos como instituições ligadas ao movimento de Educação Matemática tiveram uma participação fundamental no desenvolvimento científico da Matemática. A evidência dessa inter-relação pode ser aquilatada pela presença e pela vitalidade de Grupos de Pesquisa que foram se constituindo no país, congregando pesquisadores que transitam pela fronteira entre essas duas áreas, cujos trabalhos promovem articulações entre História, Filosofia, Educação e Matemática.

Apesar da crescente visibilidade desse movimento no cenário nacional, a partir dos centros pioneiros, localizados exclusivamente no estado de São Paulo, quando se trata de outras regiões, mais distantes geograficamente, podemos acusar o seu caráter ainda muito incipiente, com iniciativas ainda muito pontuais. É o caso, pois, de São João del-Rei e região, onde as histórias da Matemática e da Educação Matemática ainda estão por serem escritas. Sabemos que a participação das cidades históricas mineiras foi de fundamental importância na construção da nação brasileira. Por essas cidades circulou durante muito tempo, especialmente no século XVIII, não só o ouro mas também o capital cultural do Brasil-colônia. A Trilha dos Inconfidentes ${ }^{4}$, em particular, foi palco de tropeiros, inconfidentes e bandeirantes; foi a principal rota de circulação de riquezas, notícias e ideias de liberdade; testemunhou o nascimento e o esplendor do barroco mineiro. Cenário de importantes episódios da história de Minas Gerais e do Brasil, essas cidades guardam uma parte significativa do nosso patrimônio artístico-histórico-cultural. Uma boa parte desse patrimônio, constituída por documentos e material bibliográfico, disperso em variados acervos pelas diversas localidades, ainda está inexplorada ou é desconhecida dos pesquisadores em História da Matemática.

\section{O acervo do Grupo Teatral Artur Azevedo}

O acervo do Grupo Teatral Artur Azevedo está alocado na Biblioteca do Campus Dom Bosco, na UFSJ. Fundado em 1905, o Clube Teatral tinha, inicialmente, o nome de

\footnotetext{
${ }^{4}$ O Estado de Minas Gerais é subdivido em 58 "circuitos turísticos", cada um deles formado por um conjunto de municípios cujas afinidades culturais, sociais e econômicas permitem constituir uma identidade regional. No século XVIII, as vinte cidades que compõem o circuito Trilha dos Inconfidentes pertenceram à Comarca do Rio das Mortes, cuja sede era a Vila de São João del-Rei. Sabe-se que 12 dos 27 inconfidentes nasceram ou residiram nessa Comarca.
} 
Grupo Dramático Infantil 15 de novembro. Em 1915, passou a se chamar Clube Dramático Artur Azevedo em homenagem ao comediógrafo. O título de Grupo Teatral foi adotado somente em 1928. Um de seus sócios fundadores foi Antônio Guerra, estudioso e incentivador das artes cênicas. Escreveu uma "Pequena História de Teatro, Circo, Música e Variedades em São João del-Rei - 1917 a 1967”, importante compilação de dados sobre a história do teatro. O Acervo Particular de Antônio Guerra contém: aproximadamente, trezentos livros, mais de trezentos e setenta peças teatrais manuscritas ou datilografadas, aproximadamente, mil e oitocentas peças teatrais impressas em português, espanhol, inglês e francês, além de partituras musicais impressas e manuscritas, fotos, jornais e uma coleção de 13 álbuns confeccionados pelo próprio Antônio Guerra, entre os quais se encontra um relato da História do Teatro no Interior de Minas Gerais com enorme variedade de documentação.

O grupo teatral Arthur Azevedo atuou em São João del-Rei até a década de 1970. Em 1985, sua sede foi vendida e, no local, foi instalado um supermercado. Por meio de doações, construiu sua sede própria, um teatro com mil lugares, onde havia uma biblioteca que continha cerca de oito mil volumes, tratando dos mais variados assuntos. O acervo, aberto ao público, possui cerca de cento e vinte textos manuscritos e/ou datilografados de peças teatrais e o conjunto bibliográfico abrange os mais variados temas, como literatura, teatro, geografia, matemática, contabilidade e história, guardados pelo Grupo de Pesquisas em Artes Cênicas da UFSJ - GPAC desde $1992^{5}$.

\section{Os manuscritos de Anníbal Marques da Costa}

A obra "Matemática em versos e prosas" é constituída de dois volumes (Figura 1), repletos de problemas matemáticos cujos enunciados e, muitas vezes também as soluções, apresentam-se em forma de versos. O primeiro caderno, mais volumoso, intitulado "Mathematicas em Versos", começou a ser produzido em 18 de janeiro de 1942 e foi finalizado em 1 de março do mesmo ano. O segundo, de tamanho menor, sob o título "Mathem. em Versos e em prosas", traz o dia 2 de janeiro de 1954 como marco do início da sua redação, que foi concluída em fevereiro do mesmo ano. Em ambos os volumes, encontramos diversas folhas avulsas, inseridas entre uma página e outra, contendo novos problemas ou novas soluções de problemas já tratados, além de poemas, reflexões e/ou observações do autor sobre temas por ele abordados em épocas anteriores. Essas folhas avulsas foram escritas em momentos diferentes, e as datas que encontramos em algumas delas permitem-nos inferir que os manuscritos foram mantidos por muitos anos e eram frequentemente revistos pelo autor. No caderno maior, por exemplo, há inclusão de páginas com datas que vão de 1955 a 1960 - 18 anos após a sua produção. Já no caderno menor, encontramos referências do autor, no próprio texto, a trabalhos de matemática que ele teria realizado em períodos que variam de 1907 a 1954 . O texto exibe uma caligrafia muito bem cuidada (Figura 2) e está escrito em linguagem simples e acessível, a despeito das diversas incorreções ortográficas e gramaticais, conforme alerta o próprio autor:

\footnotetext{
${ }^{5}$ Para mais informações e consulta à base de dados do acervo, deve-se acessar o endereço: <http:// www.acervos.ufsj.edu.br/site/acervo_teatrais/apresentacao.html> 
"Caso, se a mim coubesse, destes excellentes preparos, todos os trabalhos, que até hoje, tenho feito, poderia, ser de melhor ilogio, de toda a provação, despertando, todo o gosto e interesse para os senhores leitôres!... Mas, por esta falta, de que por Deus, a mim não foi confiado, peço aos amigos de todas as bellas sciencias litteratas, em desculpar-me de algumas faltas, comettidas, dos meus pequenos trabalhos, tanto em Portugues e como, em sciencias Mathematicas!..."

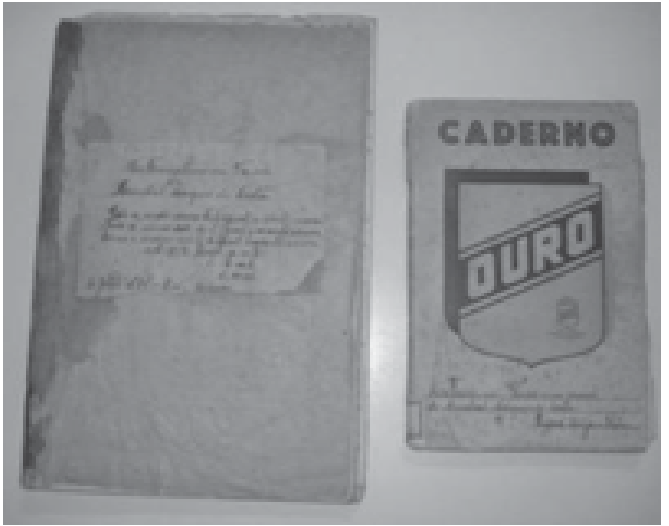

Figura 1. Frontispício dos dois volumes manuscritos.

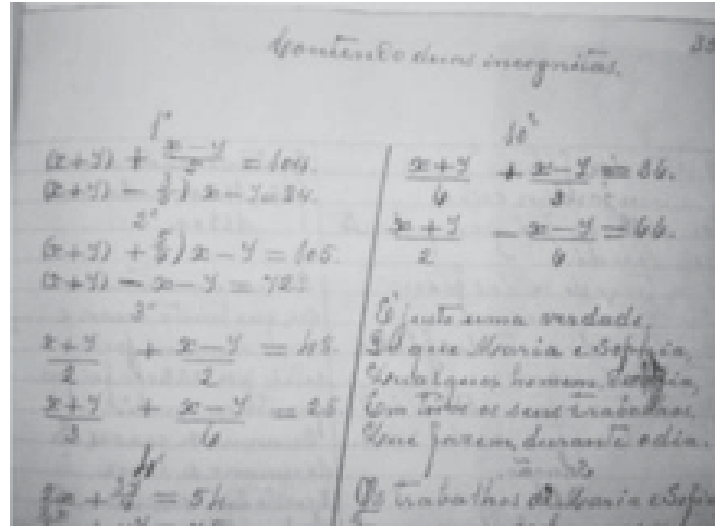

Figura 2. Fragmento da página 32 do volume.

A despeito das advertências que encontramos, em várias passagens do texto, sobre sua "pouca instrução", Anníbal demonstra conhecer não só os assuntos que escolheu para tratar em sua obra como, também, outras obras e outros autores. O professor de matemática Antônio Bandeira Trajano, ex-presidente do Supremo Concílio da Igreja Presbiteriana do Brasil, é citado por Anníbal em diversos momentos. Trajano publicou muitos livros de matemática para o Ensino Básico e, também, para o Ensino Superior, bastante utilizados na época de Anníbal, alguns deles sendo reeditados dezenas de vezes.

Não detectamos, em nenhum momento nos "versos", equívocos nos procedimentos ou regras utilizadas, nem tampouco incorreções nas propriedades ou conceitos matemáticos abordados. Os problemas propostos nos manuscritos contemplam tópicos da matemática elementar que, em sua maioria são, ainda hoje, ensinados nas escolas de nível básico. O primeiro caderno começa com problemas envolvendo as quatro operações fundamentais da aritmética ou equações do primeiro grau com uma incógnita. Os versos aritméticos são listados como numa cantilena, nem sempre constituindo problemas a resolver:

"15 vezes trinta e nove,

deduzindo trinta e oito; 
Souto, R. M. A.; Silva, S. F.

são onze vezo mesmo numero

dando mais cento e deroito"

$\mathrm{Na}$ linguagem atual, esse verso seria traduzido pela expressão $15.39-38=11.39$ + 118, que é uma sentença matemática verdadeira.

Nos problemas de uma variável, a solução apresentada é, algumas vezes, obtida por métodos algébricos utilizados atualmente. Outras vezes, a solução apresenta-se após a sugestão de uma sequência de procedimentos aritméticos, baseados em cálculos mentais, que deve ser seguida como um receituário. O exemplo abaixo, extraído do texto, ilustra esse fato.

"Rosinha tem onze anos,
Sinhazinha tem dezenove,
Com treis vez os de Maria
A somma é noventa e nove."

Atualmente, resolveríamos o problema por meio da equação $3 x+30=99$, cuja solução é 23 .

A solução apresentada por Annibal é a seguinte:

"Ora vemos q. os annos q. tem Rosinha, Juntando aos de Sinhasinha;

São trinta annos, destas mocinhas!

Com 3 vezes os de Maria, dá 99, então; menos 30, resta 69, sendo 3 vezes

os de Maria, que dividindo por 3, dá 23 anos que tem a bella Maria!"

O autor prossegue aumentando o nível de dificuldade dos problemas, que passam a envolver, também, equações com duas variáveis, equações quadráticas e sistemas com três equações e três incógnitas:

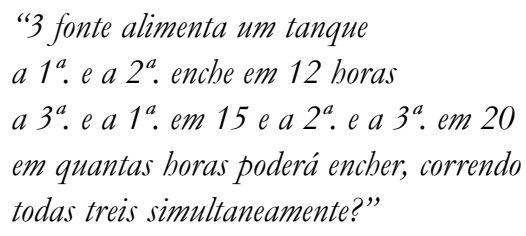

Depois de dedicar dez páginas às equações e sistemas de equações, Anníbal passa a tratar de tópicos relacionados à matemática comercial e financeira - juros simples, juros compostos, regras de sociedades (ou de "companhias"). O autor, a despeito da ressalva que faz ao leitor, de que só irá tratar de "casos mais simples e fácil de resolver", demonstra habilidade em lidar com diversas situações que envolvem esses conceitos, realizando cálculos, convertendo taxas equivalentes, fazendo divisões proporcionais e criando situações complexas no âmbito das relações comerciais e das operações financeiras. É o que mostra o exemplo a seguir. 
Annibal Marques da Costa e a "Matemática em versos e prosas"...

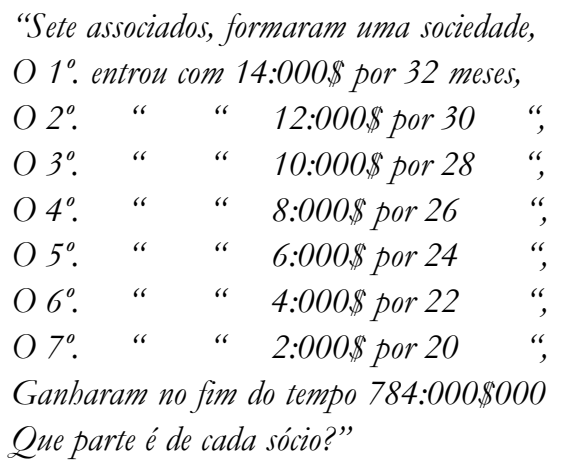

Nesse caso, o autor afirma utilizar, para resolver o problema, um processo mais antigo, porém mais simples, diferente "do processo conhecido em todos os compêndios". Nessa passagem do texto, é interessante notar a precisão do autor na condução do raciocínio, sua capacidade de expor, com clareza, o método por ele adotado e a exatidão dos seus cálculos, conduzindo o leitor à solução do problema.

No trabalho de Anníbal, alguns problemas nos chamaram a atenção não somente pelo conteúdo matemático envolvido ou pelo método de solução empregado, mas, também, pelos elementos do contexto da época em que vivia o autor, revelados nas linhas e entrelinhas dos versos. É o caso, por exemplo, da educação das mulheres e da desigualdade entre os sexos, reveladas nos exemplos a seguir.

"Em um colégio, haviam um certo no. de meninas, não estando, em parte, das que estudavam Portugues e Mathematicas.

A metade do numero,

Estavam crivando,

Um terço do numero,

Estavam bordando,

Um dezoito avos

Costurando

E vinte crochetando.

Quantas meninas

Estavam crivando?

Quantas estavam bordando?

E quantas costurando?"

"Um homem contractou, 48 pessoas, sendo homens, e mulheres pagando cada homem $4 \$ 000$; e cada mulher, $1 \$ 500$. No fim do trabalho, receberam $117 \$ 000$. Quantos homens e quantas mulheres, foram contractados para este fim?"

Os problemas matemáticos do primeiro volume ocupam 59 páginas, em um total de 96. As páginas que sobram são preenchidas com poemas, ora de autoria desconhecida, ora atribuídos a Casimiro de Abreu, a Alberto de Matos ou a Antonio Trajano, além de outros 
Souto, R. M. A.; Silva, S. F.

assinados pelo próprio Anníbal Marques da Costa. A obra encerra-se com os "Canticos Arithmeticos" e outros poemas que falam de matemática:

"Terminada as suas obras,

Ao findar o sen trabalho!...

O que mais, tenho a dizer?

Completar todo o ensino,

Outra nova mais a dar;

É a Nova Chave da Arithmetica,

E da Algebra Elementar.

As poucas linhas que tem

P'ra findar o meu trabalho;

Vou acabar, com alguns problemas.

Lido, em versos, ou cantado;

Como seja apreciado."

(1-3-1942. Domingo)

O segundo volume da "Mathematica em versos e prosas" apresenta, da mesma forma que o primeiro, a maioria dos enunciados dos problemas propostos em versos. Muitos deles são seguidos da observação "é uma modinha, probl. cantado":

$$
\begin{aligned}
& \text { "Qual será a sexta parte, } \\
& \text { de } x \text { menos trinta e oito; } \\
& \text { se } 2 x \text { e mais vin'toito, } \\
& \text { faz } 3 \times \text { menos dezoito } \\
& x=46 "
\end{aligned}
$$

Os conteúdos contemplados são: equações lineares com uma ou duas variáveis, equações quadráticas, razões e proporções, sistemas de equações lineares e matemática financeira. Ao longo do texto, Anníbal menciona outros trabalhos seus, produzidos em diversos momentos, cujas datas apresentadas pelo autor variam de 1907 a 1954:

"Faço sciente, aos srs. leitores, que em vista dos meus trabalhos, que tenho feito, a contar de 1907 até este vigor, de 1954” (...) são trabalhos muito simples"(...) "não sendo impresso, em volumes, como são, dos grandes autores, em diversos modos".

"Vou relembrar-me agora em alguns pontos de um pequeno trabalho que fiv, no anno de 1908, com o título Caderno Encantado de Flores - B".

Em outras passagens, o autor expressa a sua angústia por não ter "excellentes preparos" e se desculpa pelas faltas cometidas nos seus trabalhos "tanto em Portugues como, em sciencias Mathematicas": 
"trago em melhor desenvolvimento, mesmo, não estando eu, a par, de todos os casos desta tão bella sciencia, visto, não ter frequentado Collegios de instrucões Superiores, de todo ensino, como assim dizer, Escola Normal, Ginasio"(...) "se melhor não posso desenvolver-me, foi por falta de verba, que não pude mais avançar".

O autor resolve, ao longo do trabalho, inúmeras equações, algumas delas fracionárias. É interessante notar, em algumas soluções apresentadas, além da resposta correta, uma prova da exatidão dos cálculos, procedimento comum na resolução de exercícios de matemática na época. Abaixo, um exemplo extraído do texto:

$$
\begin{aligned}
& \text { Seja }(x+144) / 15=2 x / 3-15 \\
& \text { Solução: } \\
& \text { Seja } x \text { o número } \\
& \text { Então } x+144=10 x-225 \\
& 10 x-225=x+144 \\
& 10 x-x=225+144 \\
& 9 x=369 \\
& x=41 \\
& \text { Prova. }(41+144) / 15=12,1 / 3 \\
& 2 / 3 \text { de } 41=271 / 3 \\
& 271 / 3-15=121 / 3 \\
& \text { Logo }(41+144) / 15=41.2 / 3-15
\end{aligned}
$$

Nesse segundo manuscrito, de 181 páginas, cerca de noventa são dedicadas aos problemas matemáticos. As demais, como no primeiro caderno, são preenchidas com poemas diversos. Também como no primeiro volume da obra aqui analisada, alguns problemas têm um enunciado confuso ou ambíguo e nos foi possível compreendê-los a partir da solução apresentada, como no exemplo abaixo.

'Há dois números que somam 104.

de um d'elles tirando 14; e de outro menos 4

sendo dada a diferença; menos dois, 44."

Que Anníbal equaciona da seguinte forma:

$$
\begin{gathered}
x+y=104 \\
x-x / 4-(y-4)-2=44
\end{gathered}
$$

O autor de "A Matemática em versos e prosas" demonstrou um grau razoável de compreensão de muitos tópicos da matemática elementar e muita destreza na resolução dos inúmeros problemas propostos. A análise de sua obra nos remeteu, em diversos momentos, a um episódio bem conhecido da História da Matemática: Bhaskara e o seu Lilavati. Bhaskara (1114-1185) foi um importante matemático indiano do período medieval, o mais proeminente 
de seu tempo. Lilavati era o nome de sua filha e foi o título de seu tratado mais conhecido, um trabalho sobre aritmética e medição, escrito em versos, que repercutiu durante muitos séculos no Oriente. Os indianos tinham por hábito escrever seus textos aritméticos, especialmente os escolares, em versos, propondo problemas como quebra-cabeças (CAJORI, 2007). Os matemáticos indianos medievais dedicaram muitos de seus esforços a resolverem problemas de investimento, descontos, regras de sociedade e equações lineares e quadráticas, escrevendo-os em versos e dando-lhes uma roupagem mística e, para os não iniciados no assunto, até mesmo obscura. O Lilavati, de Bhaskara, era composto por cerca de 278 versos.

O estudo do manuscrito de Anníbal Marques da Costa não nos permite fazer afirmações conclusivas, mas nos levou a suspeitar de que o autor pudesse ter conhecimento desses fatos da História da Matemática, os quais poderiam até mesmo tê-lo inspirado na elaboração de seu trabalho. Essa possibilidade coloca-se ainda mais plausível se considerarmos, além do bom conhecimento de Anníbal sobre os temas tratados nos "versos" e as referências que ele faz a livros e autores de textos matemáticos, o fato de que a História da Matemática estava em voga nos manuais e livros escolares de seu tempo. Nas primeiras décadas do século XX, referências à História da Matemática eram comuns em textos didáticos, consequência das recomendações feitas pelos mentores e divulgadores das diversas reformas que tentaram modificar o ensino secundário no Brasil e, particularmente, o ensino de matemática. Um exemplo disso pode ser encontrado nas instruções pedagógicas da reforma Francisco Campos, iniciada em 1931, que recomendam entremear os cursos de matemática com "ligeiras alusões a problemas clássicos e curiosos e aos fatos da história da Matemática, bem como à biografia dos grandes vultos desta ciência" (BICUDO, 1942, p. 157).

\section{O poeta Beija-flor}

Ao longo da investigação que conduzimos e que relatamos aqui, diversas tentativas foram feitas no sentido de se obterem informações sobre o autor da "Matemática em versos e prosas". Apesar de nossos esforços, foram poucas as informações que conseguimos que pudessem acrescentar algo àquelas que já tínhamos ao iniciarmos este trabalho. O estudo atento da obra de Anníbal permitiu-nos tirar algumas conclusões importantes cuja plausibilidade foi reforçada pelas notas encontradas em jornais da época. Temos indícios de que Anníbal Marques da Costa tenha sido natural de São João del-Rei e que nasceu na segunda metade do século XIX, embora não nos seja possível precisar nenhuma data sobre seu nascimento ou morte. Nos manuscritos encontramos referências a trabalhos anteriores escritos em $1907 \mathrm{e}$, portanto, ao escrever a "Matemática em versos e prosas", ele, certamente, já contava mais de quarenta anos. Conhecido na cidade pela alcunha de "Poeta Beija-flor", era homem de modos simples, desprovido de posses, amante das letras e dos números e, embora, sem os "lustros da instrução", dedicou-se ao estudo da matemática. Sua obra, conforme já observamos em parágrafos anteriores, pode ser considerada de boa qualidade no que tange ao conteúdo matemático. Nela, Anníbal demonstra grande habilidade para lidar com temas variados da matemática elementar, e não se verificam incorreções ou equívocos nas soluções dos problemas tratados. Isso, por si só, já representa um feito notável para a época se atentarmos para as condições precárias do sistema educacional brasileiro que mantinha a maioria da população sem condi- 
Annibal Marques da Costa e a "Matemática em versos e prosas"...

ções de acesso à instrução formal. No que diz respeito à matemática, sabemos que sua importância como disciplina escolar na formação geral do indivíduo começou a ser reconhecida tardiamente. Os primeiros passos para esse reconhecimento foram dados na Reforma Benjamin Constant (1890), que, ao delinear uma formação científica nos moldes positivistas para o ensino secundário no Brasil, atribuiu um lugar de honra para a matemática. No entanto, somente a partir da década de 1920, com o movimento da Escola Nova, é que começou a se alterar profundamente a fisionomia da educação em nosso país. $\mathrm{O}$ ensino secundário, que o autor dos "versos" declara não ter cursado, começou a ser estruturado no Brasil somente a partir de 1931, com a Reforma Francisco Campos. Nessa época, o ensino de nível médio assumiu um caráter mais educativo e a matemática passou a figurar como disciplina importante para a formação geral do indivíduo (MIORIM, 1998). Nesse período, Anníbal Marques da Costa já escrevia seus textos matemáticos, que demonstram domínio dos conteúdos que eram objeto do ensino secundário, habilidade adquirida, provavelmente, à maneira autodidata. Em seus escritos, o poeta Beija-flor faz algumas observações acerca da produção dos "versos matemáticos" e, entre essas, encontramos uma que diz: "escrito a 30 de junho de 1958, na Biblioteca". Acreditamos tratar-se, aqui, da Biblioteca Municipal Batista Caetano D’Almeida, de São João del-Rei, primeira biblioteca pública da Província de Minas Gerais, inaugurada em 1827. Em 1828, seu acervo contava com cerca de mil volumes que, segundo o viajante inglês e pastor protestante Robert Walsh, "estavam dispostos ao longo das paredes, numa sala bem arrumada, com uma mesa de leitura no centro" (WALSH, 1985, p. 78). Desde então, esse estabelecimento desempenhou um papel importante na vida intelectual da cidade, constituindo um elemento fundamental nas estratégias de difusão do letramento na antiga Vila de São João del-Rei. Nos documentos que analisamos, há indícios de que foi nessa Biblioteca que Anníbal Marques da Costa escreveu boa parte dos seus versos matemáticos.

A obra de Anníbal, embora de pouca repercussão, parece ter sido reconhecida nos ambientes intelectuais da época. Um claro sinal disso é a sua presença e conservação em meio a tantas outras obras que compõem o acervo do Clube Teatral Artur Azevedo. Alguns de seus contemporâneos, ao que tudo indica, consideraram-na digna de ser preservada, como se pode perceber numa nota que encontramos, publicada por Gentil Palhares, no Jornal do Poste, em 19 de junho de 1967:

Entre as obras de autores são-joanenses - antigos e modernos: Augusto Viegas, Belini, Mourão Filho, Basílio de Magalhães, se alinham as dos amigos Cintra, Fábio, Edmundo Dantés, Lincoln de Souza e os rabiscos de Gentil Palhares. Mas, desses autores são-joanenses, lá está um deles, poeta livre, sem a disciplina das métricas e das rimas: algo muito interessante e curioso e a sua produção em manuscrito, versos bem inspirados, conquanto sem o rigor ou nenhum rigor mesmo... dos requisitos exigidos. Trata-se do poeta Beija-flor - Aníbal Marques da Costa - que, durante muitos anos trabalhou no Café Rio de Janeiro. Homem sem os lustros da instrução, mas que, a despeito de tudo, faz versos curiosos e dignos de serem lidos. A sua Matemática em Versos deve ser conhecida de todos, de um Cintra, de um Fábio, Dr. Augusto Viegas, Adenor Simões, dêsse admirável Dr. Salomon, dos nossos pro- 
Souto, R. M. A.; Silva, S. F.

fessôres, há homens de letras e de profissionais liberais, enfim, deve ser conhecido por todos que se interessam pelo que é nosso. É um manuscrito curioso, pitoresco e digno de ser difundido pelos nossos homens de culturas. Numa caligrafia muito bonita e floreada, encontramos esta produção. [...] É algo interessante a Matemática-em-Versos do Poeta Beija-Flor, vale a pena conhecer tudo aquilo!!! (PALHARES, 1967, p. 317)

A ligação do nome de Anníbal Marques da Costa com o antigo Café Rio de Janeiro (Figuras 3, 4 e 5) ajudou-nos a elucidar alguns pontos dessa história. Já vimos que o autor dos manuscritos não fora homem "ilustrado nas ciências ou nas artes", que era muito aplicado no estudo da matemática e que "não sendo formado nesta sciencia", nutria por ela "amor e gosto". Embora não tenha frequentado escolas nem mesmo de nível secundário, sua presença constante no Café Rio de Janeiro, como funcionário desse estabelecimento, pode ter influenciado e direcionado seu talento para os estudos e contribuído para a sua iniciativa de escrever os versos de matemática. O café Rio de Janeiro era um estabelecimento sofisticado, frequentado pela elite sanjoanense, nas décadas de 1920, 1930 e 1940. Lá não entravam crianças e as mulheres entravam muito raramente, só mesmo em ocasiões especiais. Era o local predileto de intelectuais, políticos e dos homens de negócios, palco de muitas discussões, articulações políticas e decisões que afetavam o destino de São João del-Rei e região. Vale lembrar que, desde os temos imperiais, São João del-Rei era um centro comercial importante, exportando gêneros de primeira necessidade para a Corte e para as demais províncias, e que, ainda na primeira metade do século XIX, possuía uma vida cultural bastante ativa. Mais uma vez, encontramos, nos relatos de viagem de Walsh, referindo-se aos anos 1820, que:

a cidade de São João é considerada, depois de São Paulo, a mais liberal e ativa, intelectualmente, de todo o Brasil. Seus habitantes são, de um modo geral, muito inteligentes. Eles apoiaram com entusiasmo as diferentes medidas sucessivamente adotadas em favor da independência do país, sendo firmes e sinceros apologistas do sistema constitucional e contrários à anarquia e ao despotismo" (WALSH, 1985, p. 79).

Também na primeira metade do século XIX, o baixo número de instituições de ensino e a busca por "escolaridade" demandam outros espaços de letramento, como as bibliotecas, gabinetes de estudo e sociedades literárias. Em São João del-Rei, foram criadas alternativas diversas de espaços públicos onde cidadãos do sexo masculino podiam se reunir para ler e debater os problemas de seu tempo. Exemplos desses espaços eram: as "instituições musicais", "Livraria pública", "Sociedade politécnica" e a imprensa local. No século XIX, locais de sociabilidade, como cafés, clubes, sociedades literárias etc., começam a se delinear como "esfera pública" de debates predominantemente masculina e burguesa (MORAIS, 2002, p. 58). Reflexos dessa atmosfera intelectual podem ser percebidos, ainda, nas primeiras décadas do século XX em São João del-Rei. Anníbal Marques da Costa, homem curioso e dedicado ao estudo da matemática, frequentou, pelo que pudemos verificar em nossas fontes, tanto a Biblioteca como o Café Rio de Janeiro, este último na qualidade de funcionário. São João del-Rei, 
nas décadas de 20, 30 e 40 do século XX, possuía vários "cafés" - Java, Ideal, Avenida, República e o aristocrático Rio de Janeiro, que diferenciava-se dos demais pelo "glamour" e pela atmosfera intelectual que o envolvia. Localizado na esquina das atuais avenidas Tancredo Neves e Artur Bernardes, permanecia aberto de domingo a domingo, porém, somente até as 22 ou 23 horas. Como os demais estabelecimentos desse gênero, não era propriamente um restaurante. Ali, onde só se entrava se estivesse "bem trajado", degustavam-se bebidas variadas, chás e sorvetes. Havia os frequentadores do dia e os da noite. Com o tempo, o estabelecimento foi deixando de ser interdito às mulheres, que passaram a frequentá-lo nas tardes em que podiam saborear um sorvete acompanhado, sempre, de um copo de água com gelo. Nesse período, de ebulição no plano artístico-cultural, esteve no auge, também, o Clube Teatral Artur Azevedo, em cujo acervo bibliográfico-documental, ainda hoje preservado, encontramos os manuscritos de Anníbal Marques da Costa. Com a eclosão da Segunda Grande Guerra, intensificam-se, nos espaços públicos, os debates sobre o clima político e os efeitos do conflito mundial nos rumos da sociedade. No Brasil, surge e intensifica-se a hostilidade aos italianos, inimigos dos países aliados aos Estados Unidos na guerra, entre os quais estava o Brasil. O Café Rio de Janeiro, cujo proprietário, Sr. Alfredo Mauro, era italiano, passou a ser hostilizado pela população que, num momento de alvoroço patriótico, decidiu depredá-lo. Conta-se que a depredação foi evitada graças à habilidade de alguns políticos locais, entre eles Tancredo Neves, que com discursos eloquentes convenceram a multidão e desviaram os rumos da sua momentânea investida nacionalista ${ }^{6}$. A partir desse episódio, o proprietário do Café, desgostoso com a situação, vendeu-o para outro comerciante local. Na década de 1950, o Café foi demolido e o seu lugar na preferência da nova geração de políticos e intelectuais foi transferido para a Cantina do Ítalo, ainda hoje existente em São João del-Rei.

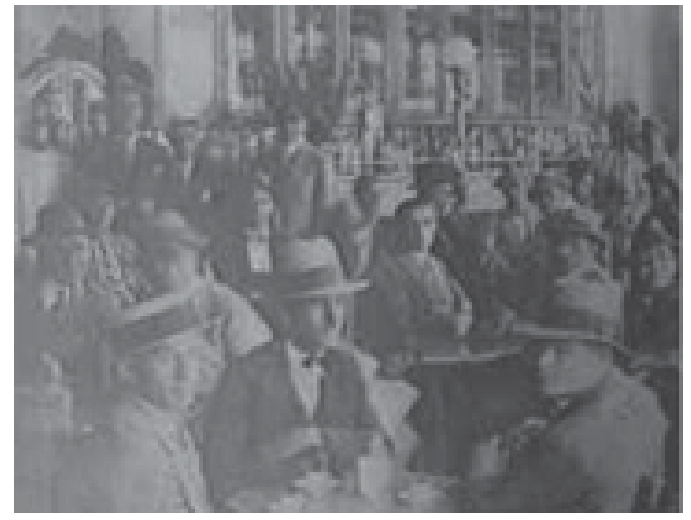

Figura 3. Interior do Café Rio de Janeiro.

\footnotetext{
${ }^{6}$ Esse e outros episódios relacionados à história do Café Rio de Janeiro são narrados por Jota Dangelo, Maria Amélia, Zininha Neves, Ginego, Berta Leite e Aura Salomé no vídeo “Café Rio de Janeiro”, produzido pelo Studio JPV.
} 

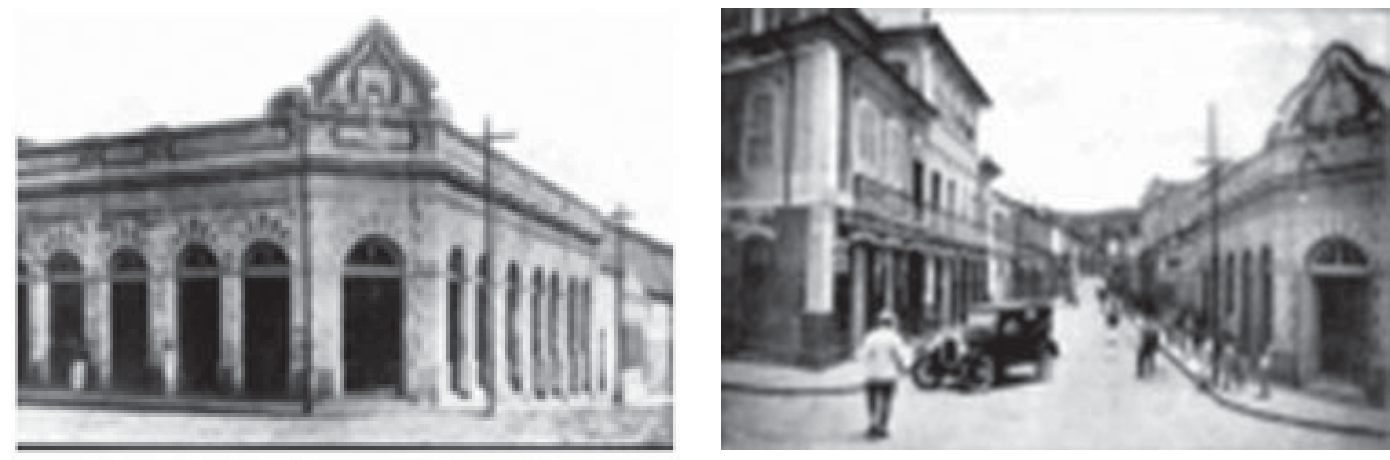

Figuras 4 e 5. Prédio que abrigava o Café Rio de Janeiro.

\section{Considerações finais}

A despeito de algumas dificuldades e, mesmo, de alguns impasses com os quais nos deparamos na tentativa de estudarmos a obra de Anníbal Marques da Costa e apreendermos o seu significado no contexto em que ela se insere, acreditamos que a investigação que conduzimos trouxe contribuições importantes para nossos estudos no campo das relações da História com a Educação Matemática em nossa região. A primeira dessas contribuições, a nosso ver, consiste na compreensão mais aprofundada da obra escrita por Anníbal e na constatação de que a matemática ali presente é de boa qualidade e que está em consonância com os princípios estabelecidos pelos movimentos modernizadores do ensino dessa disciplina naquela época. Anníbal é de um tempo em que as reformas educacionais, sobretudo aquelas que promoviam a reestruturação do ensino secundário, preconizavam a valorização de um ensino com caráter mais técnico e científico em detrimento do caráter humanístico. As tendências de reforma do ensino da matemática naquela época, além de atribuírem um papel mais importante para essa disciplina no currículo, apregoavam que seu ensino deveria ser mais "prático", mais voltado para os interesses e necessidades impostos pela vida cotidiana, menos acadêmica e menos teórica. Percebemos que o estilo adotado por Anníbal e os temas por ele escolhidos para tratar nos seus "versos" vão ao encontro dessas tendências, e temos razões para crer que essa concordância era consciente e intencional. Anníbal conhecia os manuais escolares utilizados em sua época, refere-se a professores de renome e frequentava ambientes que abrigavam debates sobre as grandes questões de seu tempo. A pouca (ou talvez nenhuma) escolaridade do autor dos "versos" e a sua condição socioeconômica desfavorecida não o impediram de estudar nos compêndios e de aprender a matemática escolar daquela época. Seu talento para a matemática e sua dedicação ao estudo dessa ciência permitiram-lhe produzir uma obra de alcance modesto, porém de boa qualidade. Mesmo não tendo sido impresso nem amplamente divulgado, seu trabalho teve uma razoável repercussão local, posto que mereceu notas em jornais da época e um lugar entre as obras guardadas no acervo do Clube Teatral Artur Azevedo. O trabalho de Anníbal possui também relevância histórica e cultural e sua análise nos permitiu compreender 
Annibal Marques da Costa e a "Matemática em versos e prosas"...

um pouco mais sobre os múltiplos laços que o ligam aos movimentos políticos e intelectuais da época. As relações de Anníbal Marques da Costa com o Café Rio de Janeiro, com a Biblioteca Municipal e o Clube Teatral Artur Azevedo foram, para nós, tão surpreendentes quanto reveladoras. Desvelar esses laços permitiu-nos conhecer um pouco mais sobre a sociedade sanjoanense na primeira metade do século XX e avivou nosso interesse pelas questões relacionadas ao ensino, aprendizagem e divulgação da matemática nos círculos de então.

\section{Referências}

BARONI, R. L. S.; TEIXEIRA, M. V.; NOBRE, S. R. A investigação científica em história da matemática e suas relações com o programa de pós-graduação em educação matemática. In: BICUDO, M. A. V.; BORBA, M. C. (Orgs.). Educação matemática: pesquisa em movimento. São Paulo: Cortez, 2005. p. 164-185.

BICUDO, J. C. (Org.). O ensino secundário no Brasil e sua atual legislação (de 1931 a 1941 inclusive). São Paulo: AIFES, 1942.

CAFÉ Rio de Janeiro - São João del-Rei. Produção Studio JPV. São João del-Rei: [s.n.], 2008. 1 VCD/NTSC (40 min), son. Color.

CAJORI, F. Uma história da Matemática. Trad. Lázaro Coutinho. Rio de Janeiro: Ciência Moderna, 2007.

CENTRO DE INFORMAÇÕES SOBRE A CIDADE - SÃO JOÃO DEL-REI - Galeria de fotos. Disponível em <http://cic.acidelrei.com.br/?Meio=album>. Acesso em: 22 abr. 2009.

D'AMBROSIO, U. Um enfoque transdisciplinar à educação e à história da matemática. In: BICUDO, M. A. V.; BORBA, M. C. (Orgs.). Educação matemática: pesquisa em movimento. São Paulo: Cortez, 2005. p. 13-29.

FIORENTINI, D.; LORENZATO, S. Investigação em educação matemática: percursos teóricos e metodológicos. 2. ed. Campinas: Autores Associados, 2007.

MIORIM, M. A. Introdução à História da Educação Matemática. São Paulo: Atual, 1998.

MORAIS, C. C. "Para aumento da instrução da mocidade da nossa pátria”: estratégias de difusão do letramento na vila de São João del-Rei (1824-1831). 2002. 158f. Dissertação (Mestrado em Educação) - Faculdade de Educação, Universidade Federal de Minas Gerais, Belo Horizonte, 2002.

PALHARES, G. Biblioteca "Aluízio Azevedo", no cine-teatro Artur Azevedo tem grandes atrações! Inclusive poeta-matemático! Jornal do Poste, São João del-Rei, p. 317-318, 19 jun. 1967. 
Souto, R. M. A.; Silva, S. F.

RICOEUR, P. La memória, la historia, el olvido. Buenos Aires: Fondo de Cultura Econômica de Argentina SA, 2004.

SOUTO, R. M. A. Obras raras e antigas sobre Matemática e áreas afins da Biblioteca Municipal Batista Caetano D'Almeida e do acervo do Grupo Teatral Artur Azevedo, em São João del-Rei/MG. Revista Brasileira de História da Matemática, Rio Claro, v. 8, n. 16, p. 181-195, 2008.

WALSH, R. Notícias do Brasil (1828-1829). Belo Horizonte: Itatiaia, 1985. v. 2 (Reconquista do Brasil; nova série).

Artigo recebido em outubro de 2010 e aceito em fevereiro de 2011. 